nephron

Practice
Nephron 2018;140:79-80

DOI: $10.1159 / 000492947$
Received: August 7, 2018

Accepted after revision: August 9, 2018 Published online: September 10, 2018

\title{
Changing Paradigms in Acute Kidney Injury: From Mechanisms to Management: Proceedings of the 8th Annual UAB-UCSD O'Brien Center Symposium
}

\author{
Kelly K. Andringa ${ }^{a}$ Ravindra L. Mehta ${ }^{c}$ Paul W. Sanders ${ }^{a, b}$ Anupam Agarwal ${ }^{a, b}$ \\ a Department of Medicine, Division of Nephrology, University of Alabama at Birmingham, Birmingham, AL, USA; \\ ${ }^{b}$ Birmingham Veterans Administration Medical Center, Birmingham, AL, USA; ${ }^{\circ}$ Department of Medicine, Division of \\ Nephrology, University of California, San Diego, CA, USA
}

Acute kidney injury (AKI) is an occurrence of kidney failure/damage that can happen within hours to a few days. The research surrounding this disease state has rapidly evolved to elucidate further the mechanisms and pathways of AKI and how these affect other organ systems and processes. Biomarkers and other small molecules have provided new tools and techniques to further characterize AKI, including genetic and epigenetic modifications, environmental influences, and the mechanisms within the kidney. Further understanding the pathophysiology of AKI offers challenging perspectives in clinical and translational research. This issue summarizes the proceedings of the 8 th annual symposium that was sponsored by the University of Alabama at Birmingham (UAB) - University of California San Diego (UCSD) O'Brien Center for AKI Research and held during the 23rd annual Continuous Renal Replacement Therapy conference in San Diego, California on March 6, 2018.

The overall goal of this symposium was to provide a comprehensive review of the most recent developments

\section{KARGER}

() 2018 S. Karger AG, Basel

E-Mail karger@karger.com

www.karger.com/nef in the study of AKI and describe emerging knowledge from basic and translational research. The meeting included 20 experts invited from around the world and over 100 participants who were in attendance. Symposium sessions focused on defining key molecules, mechanisms and targets involved in the pathogenesis, differentiation, and repair in AKI. The symposium included discussion of (1) coordination of the results of AKI studies in animal models with the human condition; (2) modalities to translate research and discoveries into the best practices for clinical care; and (3) different issues in research, diagnosis and clinical trials for researchers involved in AKI discovery.

The UAB-UCSD O'Brien Center has taken a major role in the development of scientific and clinical resources for investigators undertaking AKI-related research. The Center has been involved in identifying research trends and emerging technologies and assisting in the pursuit of opportunities through enhanced core resources, technique training and opportunities as well 
as educational enrichment through workshops and seminars. This symposium highlighted the exciting developments in the field and provided a forum for exchange of ideas among basic scientists and clinicians. The proceedings from this symposium [1-17] provide a unique collection, which we anticipate will stimulate further investigation into understanding the effects and outcomes of AKI.

\section{Acknowledgment}

This symposium was supported in part by the NIDDK funded University of Alabama at Birmingham-University of California San Diego O’Brien Center for AKI Research (P30DK079337).

\section{Disclosure Statement}

The authors have no conflicts of interest to declare.

\section{References}

1 Fiorentino M, Kellum JA: Improving translation from preclinical studies to clinical trials in acute kidney injury. Nephron 2018, DOI: 10.1159/000489576.

2 Endre $\mathrm{ZH}$ : Assessing renal recovery after AKI: can biomarkers help? Nephron 2018, DOI: 10.1159/000492290.

3 Hepokoski ML, Malhotra A, Singh P, Crotty Alexander LE: Ventilator-induced kidney injury: are novel biomarkers the key to prevention?Nephron2018,DOI: 10.1159/000491557.

4 Mannon RB: Delayed graft function: the AKI of kidney transplantation. Nephron 2018, DOI: $10.1159 / 000491558$

5 Neyra JA, Leaf DE: Risk prediction models for acute kidney injury in critically Ill patients: opus in progressu. Nephron 2018, DOI: 10.1159/000490119.

6 Romagnoli S, Ricci Z, Ronco C: Perioperative acute kidney injury: prevention, early recognition, and supportive measures. Nephron 2018, DOI: $10.1159 / 000490500$.
7 Palevsky PM: Endpoints for clinical trials of acute kidney injury. Nephron 2018, DOI: $10.1159 / 000493203$.

8 Wilson FP, Greenberg JH: Acute Kidney Injury in Real Time: Prediction, Alerts, and Clinical Decision Support. Nephron 2018, DOI: $10.1159 / 000492064$.

9 Rabb H, Pluznick J, Noel S: The microbiome and acute kidney injury. Nephron 2018, DOI: $10.1159 / 000490392$.

10 Jones TF, Bekele S, O’Dwyer MJ, Prowle JR: MicroRNAs in acute kidney injury. Nephron 2018, DOI: 10.1159/000490204.

11 Arthur JM, Karakala N, Edmondson RD: Proteomic analysis for identification of biomarkers that predict severe acute kidney injury. Nephron 2018, DOI: 10.1159/000491440.

12 Winfree S, Dagher PC, Dunn KW, Eadon MT, Ferkowicz M, Barwinska D, Kelly KJ, Sutton TA, El-Achkar TM: Quantitative large-scale three-dimensional imaging of hu- man kidney biopsies: a bridge to precision medicine in kidney disease. Nephron 2018, DOI: 10.1159/000490006.

13 Fattah H, Vallon V: Tubular recovery after acute kidney injury. Nephron 2018, DOI: 10.1159/000490007.

14 von Mässenhausen A, Tonnus W, Linkermann A: Cell death pathways drive necroinflammation during acute kidney injury. Nephron 2018, DOI: 10.1159/000490807.

15 van Groenendael R, Kox M, van Eijk LT, Pickkers P: Immunomodulatory and kidneyprotective effects of the human chorionic gonadotropin derivate EA-230. Nephron 2018, DOI: $10.1159 / 000490772$.

16 Tanaka S, Okusa MD: Optogenetics in understanding mechanisms of acute kidney injury. Nephron 2018, DOI: 10.1159/000491498.

17 Swaminathan S: Iron homeostasis pathways as therapeutic targets in acute kidney injury. Nephron 2018, DOI: 10.1159/000490808. 